Poteryaev Ilya Konstantinovich, $\mathrm{PhD}$, Assistant professor Siberian State Automobile and Highway University

Omsk, Russian Federation

E-mail: poteryaev_ik@mail.ru

ORCID ID: 0000-0002-4350-2495

\title{
CREATING A NEW TECHNICAL SOLUTION FOR BALTING BITUMEN AT AN ASPHALT-CONCRETE PLANT
}

\begin{abstract}
The article presents a technical solution for pouring bitumen on an asphalt plant. The technical solution will allow bitumen to be loaded into road sprayers for filling on the road in case of a distant location of bitumen bases. The technical solution will allow emptying the capacity of the asphalt concrete plant before its transportation to another construction site.
\end{abstract}

Key words: Asphalt concrete plant, bitumen, road sprayer, capacity, asphalt mixing plant.

Roads are very important in the modern world. During the construction of asphalt pavements bitumen is most common. Bitumen is used in the manufacture of asphalt concrete mix on the asphalt concrete plant and as a filling between the layers on the road $[1,2,3]$.

Refueling of bitumen in the road impactor is carried out on bitumen bases. If the construction object is located far from a populated area, then it is advisable to carry out refueling of the tar sprayer with bitumen from the tanks by asphalt-mixing plant. Also, if the automated control system is mobile (Figure 1), then before relocation it is necessary to pump materials, including binder, from all containers. For this, a device is needed for pouring bitumen into vehicles from asphalt-mixing tanks [4].

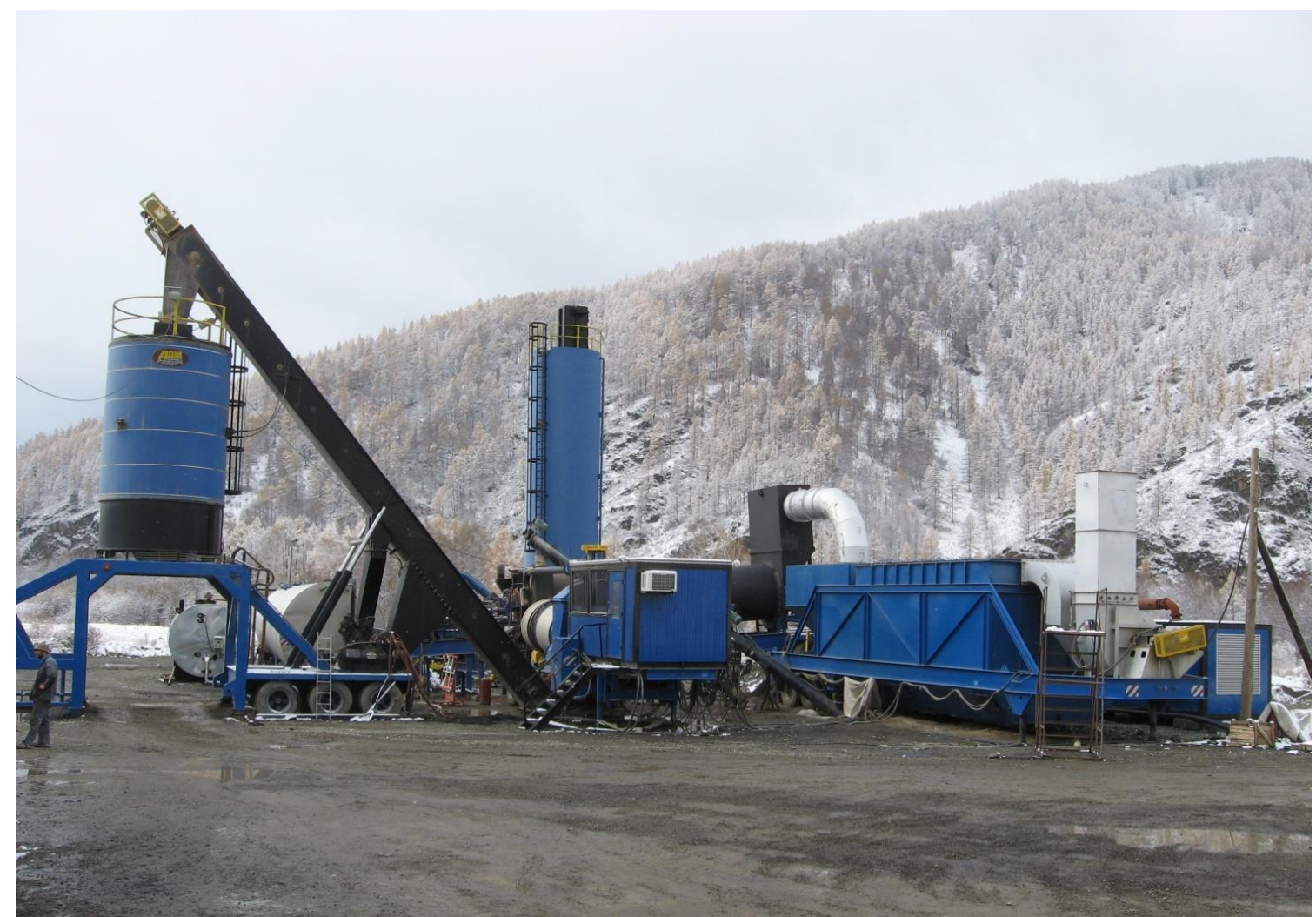

Figure 1 - Asphalt mixing plant Milemaker 160

Technical science bitumen
Materials of International Practical Internet Conference "Challenges of Science" 
The device must be heated to prevent bitumen from freezing during pouring.

The useful capacity of the pump for filling bitumen is determined on the basis of the power of the electric motor, taking into account the energy loss during its transfer from the pump to the electric motor according to the formula:

$$
N_{p p}=k_{f m} \cdot k_{s f} \cdot N_{m p},
$$

where $N_{p p}$ - pump power, kw; $k_{f m}$ - force margin, $k_{f m}=1,1 ; k_{s f}$ - speed factor, $k_{s f}=1,1 ; N_{m p}-$ motor power, $\mathrm{kw}$.

$$
N_{p p}=1,1 \cdot 1,1 \cdot 11=13,31 \mathrm{kw} .
$$

Knowing the necessary useful power of the pump, and taking into account that the useful power of the pump is associated with a new terminal pressure and flow dependency $N_{p p}=p_{p} \cdot Q_{p}$, can find the flow and displacement of the pump by the formulas:

$$
\begin{array}{r}
Q_{p}=\frac{N_{p p}}{p_{p}}, \\
q=\frac{N_{p p}}{1000 \cdot p_{p} \cdot n_{\mu}},
\end{array}
$$

where $N_{p p}$ - pump power, kw; $Q_{p}$ - pump feed, дм³ $/ \mathrm{c}, Q_{p}=q \cdot n_{H} ; p_{p}$ - pressure rating, МПа; $q$ - pump displacement, $\mathrm{cm}^{3} ; n_{\mu}$ - gearbox shaft speed, $s^{-1}$ (rpm).

Nominal frequency of rotation of the electric motor of the pump $1500 \mathrm{rpm}$.

$$
q=\frac{13,37}{0,6 \cdot 450}=50 \mathrm{~cm}^{3} \text {. }
$$

Pump choose from technical literature on two parameters: the nominal pressure of the electric drive $p_{p}$ and pump displacement $q$.

According to $q=50 \mathrm{~cm}^{3}$ и $p_{p}=0,6 \mathrm{MPa}$ suitable bitumen pump DS-125.

The pump for bitumen loading is shown in Figure 2.

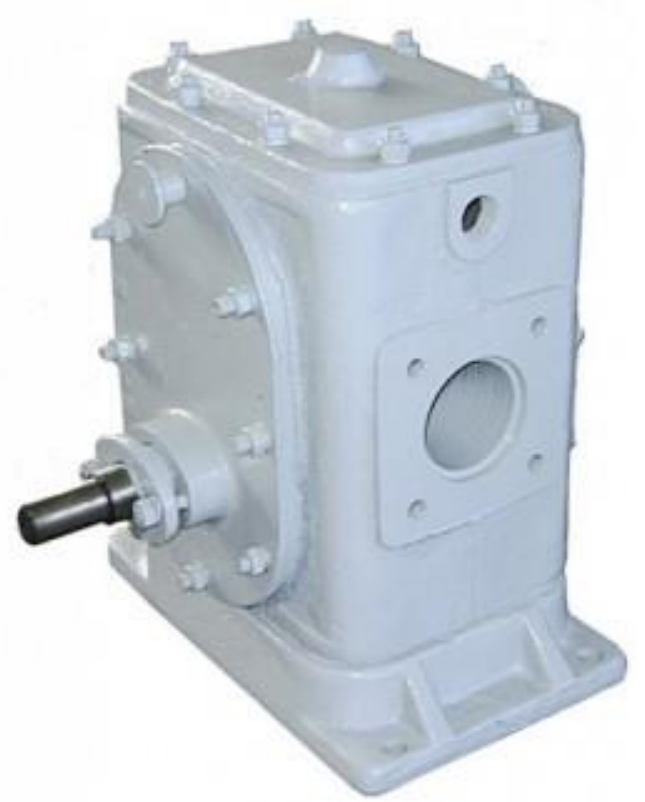

Figure 2 - Pump bitumen DS-125

Technical science bitumen
Materials of International Practical Internet Conference "Challenges of Science" 
Figure 3 shows a bitumen pump installation with selected electric motor, gearbox and pump.
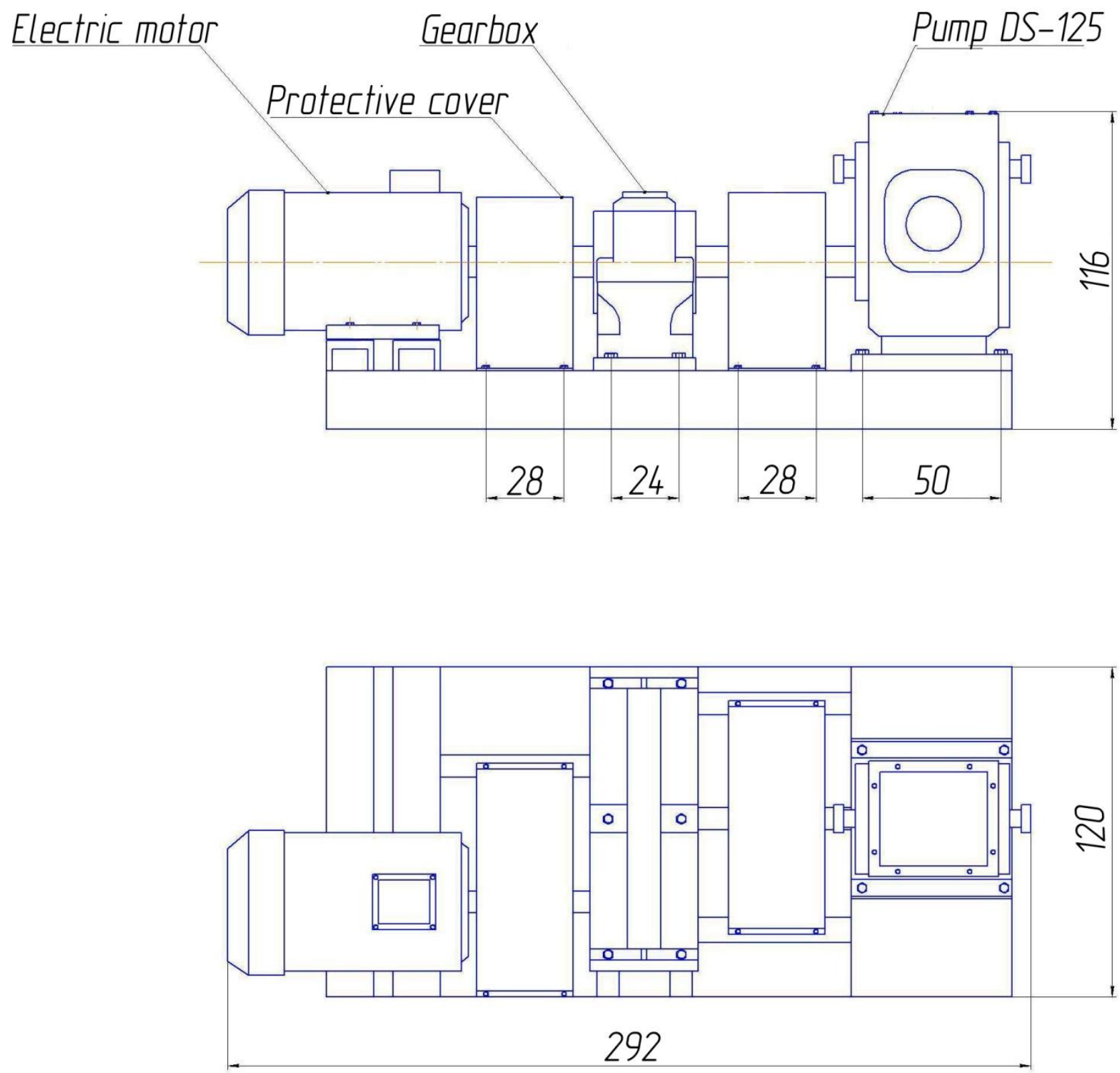

Figure 3 - Installation of bitumen pumping

The drawing of the device for bitumen loading is shown in Figure 4.

Technical science bitumen
Materials of International Practical Internet Conference "Challenges of Science" 


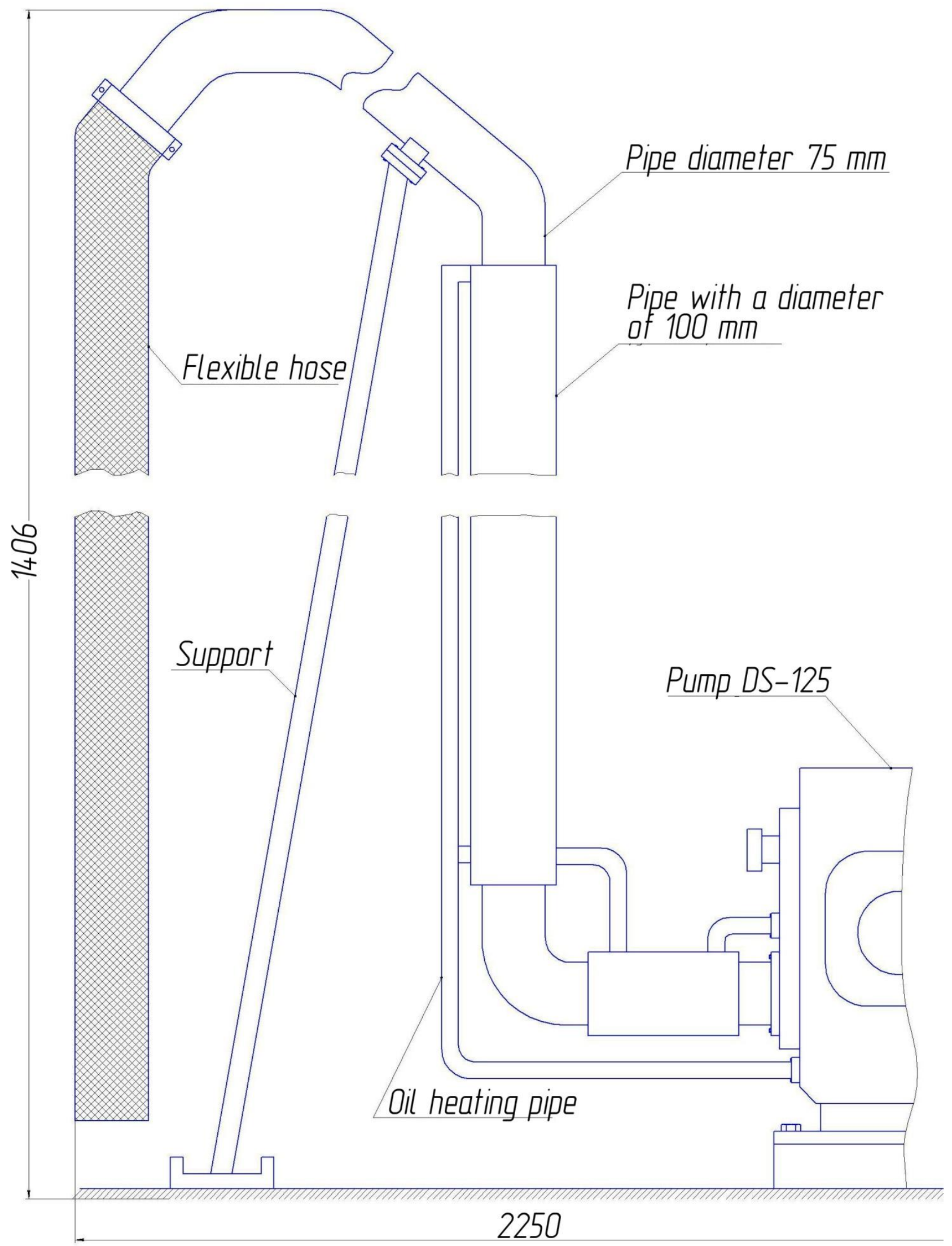

Figure 4-Bitumen loading device

Technical science bitumen
Materials of International Practical Internet Conference "Challenges of Science" 
The device will reduce the cost of bottling bitumen binder at the construction site, because when the asphalt concrete pavement is being constructed, the road sprayer far from populated areas will be able to pick up bitumen at the asphalt concrete plant, and not at the nearest bitumen stations, which are often located hundreds of kilometers away from construction projects. Also, the device will allow emptying the capacity of the asphalt concrete plant before canning it for winter storage or before preparing the asphalt mixing plant for relocation.

\section{References}

1. Permyakov V. B. Technological machines and complexes in road construction (production and technical operation): tutorial. Omsk : SibADI, 2014. 752 p.

2. Savel'ev S. V. Technical operation of construction and oil and gas equipment: a tutorial / S. V. Savel'ev, I. K. Poteryaev. - Omsk : SibADI, 2016.

3. Zubkov, A.F. Technology of construction of asphalt concrete pavements of roads : Monograph / Zubkov A.F., Odnol'ko V.G. - Moscow : Mashinostroenie. - 2009. - 224 p.

4. Technological regulations asphalt mixing plant Milemaker 160. - Omsk, 2013. 